EPJ Web of Conferences 114, 02058 (2016)

DOI: $10.1051 /$ epjconf/201611402058

(C) Owned by the authors, published by EDP Sciences, 2016

\title{
Experimental research of multiphase flow with cavitation in the nozzle
}

\author{
Milada Kozubkova ${ }^{1}$, Marian Bojko ${ }^{1}$, Jana Jablonska ${ }^{1}$, Dorota Homa ${ }^{2, a}$ and Jiří Tůma ${ }^{3}$ \\ ${ }^{1}$ Department of Hydromechanics and Hydraulic Equipment, Faculty of Mechanical Engineering, VSB - Technical University of Ostrava, \\ 17. listopadu 15, 70833 Ostrava, Czech Republic \\ ${ }^{2}$ Institute of Power Engineering and Turbomachinery, Faculty of Energy and Environmental Engineering, Silesian University of Technology, \\ Konarskiego Street 18, 44100 Gliwice, Poland \\ ${ }^{3}$ Department of Controls Systems and Instrumentations, Faculty of Mechanical Engineering, VSB - Technical University of Ostrava, \\ 17. listopadu 15, 70833 Ostrava, Czech Republic
}

\begin{abstract}
The paper deals with the problems of cavitation in water flow in the nozzle. The area of research is divided into two directions (experimental and numerical research). During the experimental research the equipment with the nozzle is under the measurement and basic physical quantities such as pressure and volume flow rate are recorded. In the following phase measuring of noise which is generated during flow through the nozzle in the area of cavitation is measured at various operating conditions of the pump. In the second part the appropriate multiphase mathematical model including the consideration of cavitation is defined. Boundary conditions for numerical simulation are defined on the basis of experimental measurements. Undissolved air in the flow is taken into account to obtain pressure distribution in accordance to measured one. Results of the numerical simulation are presented by means of basic current quantities such as pressure, velocity and volume fractions of each phase. The conclusions obtained from experimental research of cavitation were applied to modify the multiphase mathematical model.
\end{abstract}

\section{Introduction}

Cavitation is fairly common phenomenon in issues connected with hydrodynamics and pumps. Hydrodynamic cavitation, the one most common in hydraulic equipment, can be observed in areas of lowered pressure and higher velocity appearance. In pumps it is near the leading edge of rotor blades. For hydraulic equipment such as valves and rotor of pumps working under cavitation conditions can lead to their serious damage and loss of further working possibility [1]. Therefore it is crucial to be able to predict and model cavitation occurrence and development.

Cavitation is a process that includes both vaporization (creation of vapour bubbles) and condensation (sudden bubble collapse). At first, when pressure is lowered cavitation nuclei of diameter about $10^{-6} \mathrm{~m}$ occur in the flow. If the pressure is still lowered (which happens in flow through the nozzle), the nuclei start to grow due to the evaporation on their surface. This is called vapour cavitation $[2,3]$ If the lowering of pressure is taking place at slow rate the growth of the bubbles can be due to the diffusion on undissolved gases in the liquid. This is called gaseous cavitation [2,3]. When bubbles flow to the area of higher pressure and lower velocity, they collapse. The vacuum formed around collapsing bubbles causes the liquid to flow in with high velocity. The liquid compresses the left gases to the very high pressure. The gases at high pressure expand again and the vaporization at the surface of the bubble takes place. The whole process of vaporization and condensation happens alternately at high frequency. The natural frequency of bubbles is mentioned to be about $2-5 \mathrm{kHz}$ [4].

As the cavitation phenomenon is highly unsteady and includes complicated interaction between phases, there are different mathematical models describing it [5-7]. They consider mainly on vapour phase creation in the flow. In presented numerical simulation the undissolved air was taken into account to obtain the results in accordance with experiment. Aim of this paper is to confront results of the mathematical simulation with an experiment.

\section{Description of experiment}

\subsection{Experimental methods}

To widen the knowledge of the cavitation process and provide data to compare with mathematical simulation the following experiment was performed. Cavitating flow in circular converging-diverging nozzle installed in a hydraulic circuit was observed. The methods included visualisation of the flow with means of camera recording, measuring of the flow rate, pressure and noise [8].

\footnotetext{
${ }^{\mathrm{a}}$ Corresponding author: dorota.homa@polsl.pl
} 


\subsection{Experimental equipment}

Experimental equipment consisted of hydraulic circuit with circular converging-diverging nozzle, frequency converter, flowmeter, pressure and noise sensors and dissolved oxygen transmitter. The scheme of the circuit is shown in figure 1 .
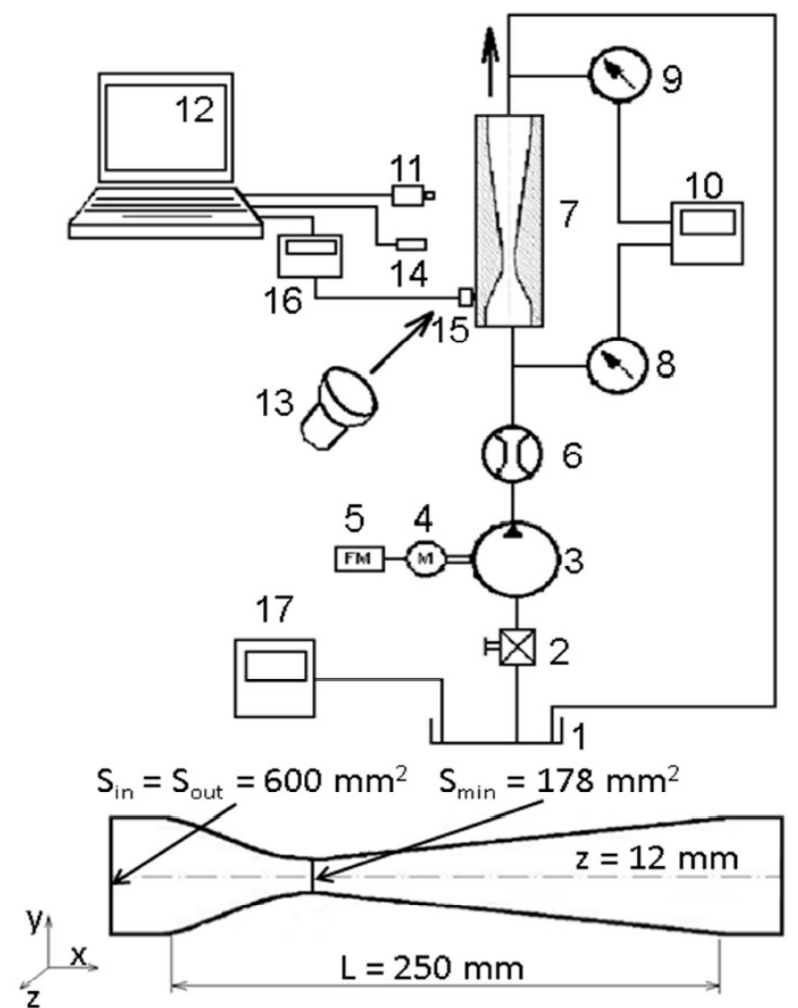

Figure 1. Measuring circuit diagram and basic parameters of the investigated object 1 - tank, 2 - ball valve, 3 - GRUNDFOS five-stage water pump, 4 - electric motor, 5 - YASKAWA VS mini J7 frequency inverter, 6 - ELIS PLZEŇ electromagnetic flow meter, 7 - measured object - nozzle, 8, 9 - Hydrotechnik pressure sensors, 10 - Hydrotechnik analyzer, 11 - Baumer HXC20c high-speed camera with CMOSIS CMV2000 sensor, 12 - PC with analysis software, 13 - light source, $14-1 / 2$ “" TYPE 489 microphones, 15 - vibration sensor, 16 - Microlog analyzer, 17 - ENDRESS + HAUSER LIQUISYS-M dissolved oxygen transmitter

The flow in the circuit was forced by the pump connected to the tank, working liquid was water. Water passed through the flowmeter and reached the nozzle. With increasing pump motor's frequency more air was released in the nozzle. The change of oxygen content in the water was measured by the dissolved oxygen transmitter located in the tank. In the beginning and end of the nozzle the pressure sensors were installed. The nozzle is made of transparent plastic. The angle of extension in the diffuser part of the nozzle is equal to $7.3^{\circ}$, which is less than the critical value of $12^{\circ}$ at which separated flow occurs [2]. The flow was regulated by changing the frequency of pump's motor by means of frequency converter. The measurements were performed at twelve different pump's motor frequencies, from $10 \mathrm{~Hz}$ to $32 \mathrm{~Hz}$ with step $2 \mathrm{~Hz}$. For each frequency noise measurement was performed by means of sound intensity probe, shown in figure 2 .

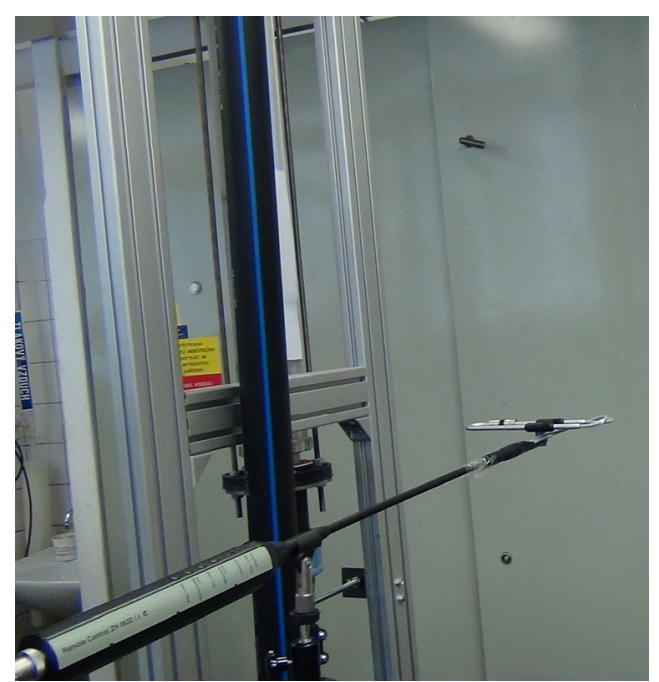

Figure 2. Sound intensity probe

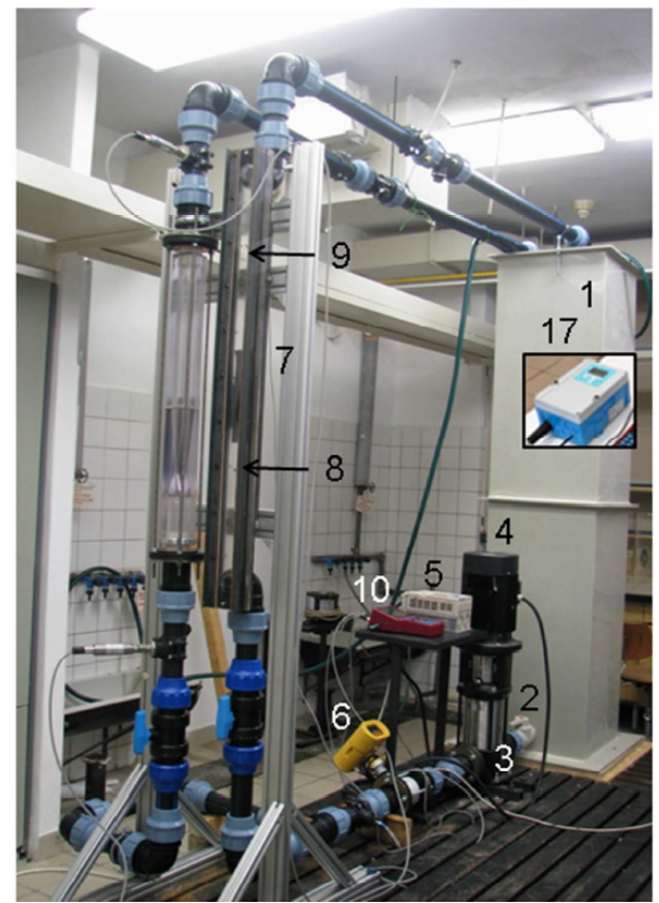

Figure 3. Measuring circuit photo

\section{Evaluation of experiment}

\subsection{Visualisation of cavitation clouds}

The cavitation could be observed from frequency equal to $18 \mathrm{~Hz}$. As cavitation is not uniform in time, for each frequency the sequence of pictures were taken. After that, the mean value of cavitation cloud area at each frequency was prepared using MATLAB software. The results of measurements including $f$ frequency of pump's motor; $Q_{v}$ mean volumetric flow of water; $p_{i n}$ mean static pressure at inlet to the nozzle, $p_{\text {out }}$ mean static pressure at the outlet to the nozzle; $L$ length of cavitation cloud are shown in table 1 . In figure 4 the clouds are plotted. 
Table 1. Results of measurements

\begin{tabular}{|c|c|c|c|c|}
\hline $\mathbf{f}$ & $\mathbf{Q}_{\mathbf{v}}$ & $\mathbf{p}_{\text {in }}$ & $\mathbf{p}_{\text {out }}$ & $\mathbf{L}$ \\
\hline $\mathrm{Hz}$ & $1 / \mathrm{s}$ & $\mathrm{Pa}$ & $\mathrm{Pa}$ & $\mathrm{cm}$ \\
\hline 18 & 2.61 & 138982 & 96476 & 1.6 \\
\hline 20 & 2.79 & 155301 & 96725 & 2.2 \\
\hline 22 & 2.95 & 173085 & 97048 & 4.1 \\
\hline 24 & 3.15 & 192279 & 97329 & 5.3 \\
\hline 26 & 3.31 & 213556 & 97775 & 7.0 \\
\hline 28 & 3.49 & 236471 & 98202 & 9.4 \\
\hline 30 & 3.68 & 260885 & 98493 & 11.3 \\
\hline 32 & 3.88 & 286609 & 97937 & 11.7 \\
\hline
\end{tabular}

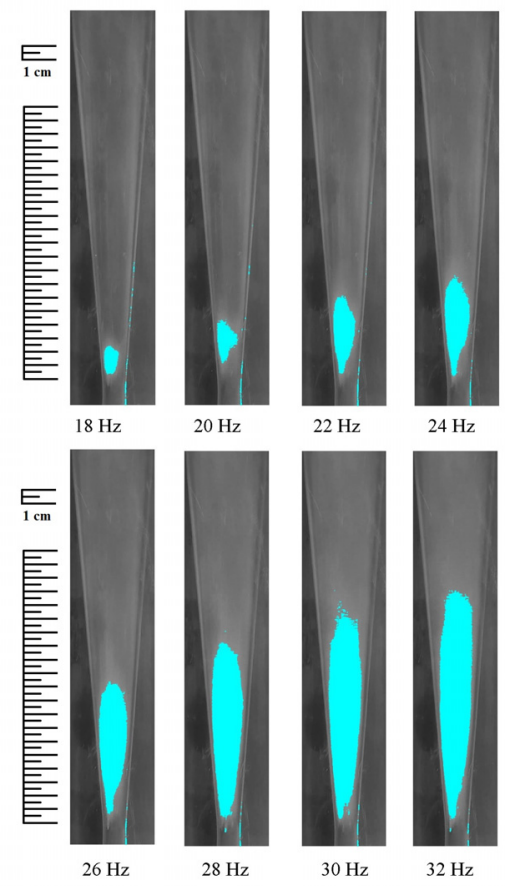

Figure 4. Cavitation clouds development

The clouds are slightly not axisymmetric as the nozzle was lit from the one side.

\subsection{Results of noise measurements}

For each frequency of the pump's motor noise generated by the flow in the nozzle was measured by sound intensity probe. As the sound probe also received signals from pump's motor, it was necessary to place it between the nozzle and the motor and reject the signal from motor's site. After collecting the data, the FFT analysis was performed to identify main noise frequencies. The results for motor's frequency from $18 \mathrm{~Hz}$ to $24 \mathrm{~Hz}$ are shown in figure 5 .

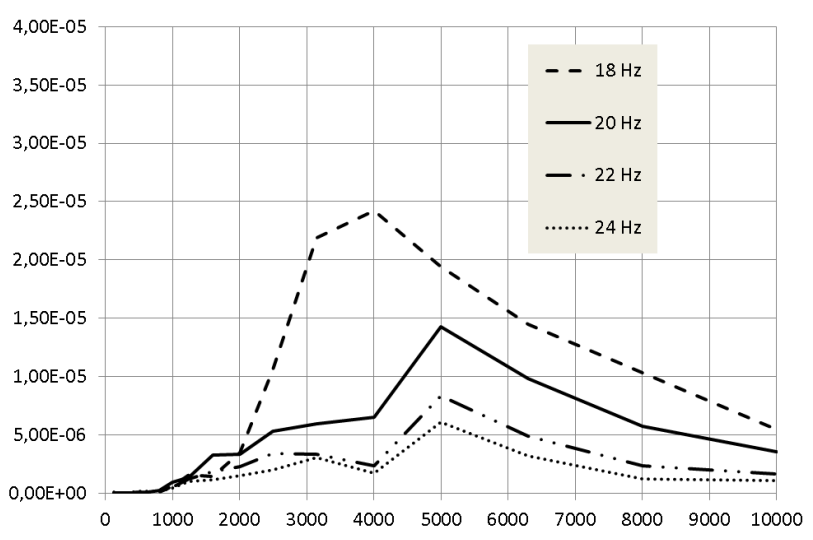

Figure 5. FFT analysis of noise measurements, frequency of motor from $18-24 \mathrm{~Hz}$

For motor's frequencies of $18 \mathrm{~Hz}$ only one peak frequency can be noticed, equal to $4000 \mathrm{~Hz}$. As the frequency and flow rate is increasing, the frequency is equal to about $5000 \mathrm{~Hz}$ and from $24 \mathrm{~Hz}(3.15 \mathrm{l} / \mathrm{s})$ the two noise frequencies can be observed, $3000 \mathrm{~Hz}$ and $5000 \mathrm{~Hz}$. For $3000 \mathrm{~Hz}$ magnitude is lower. However, from motor's frequency $28 \mathrm{~Hz}$ the higher magnitude appears at this frequency. Results of FFT analysis for further flow rates and motor's frequencies is shown in figure 6.

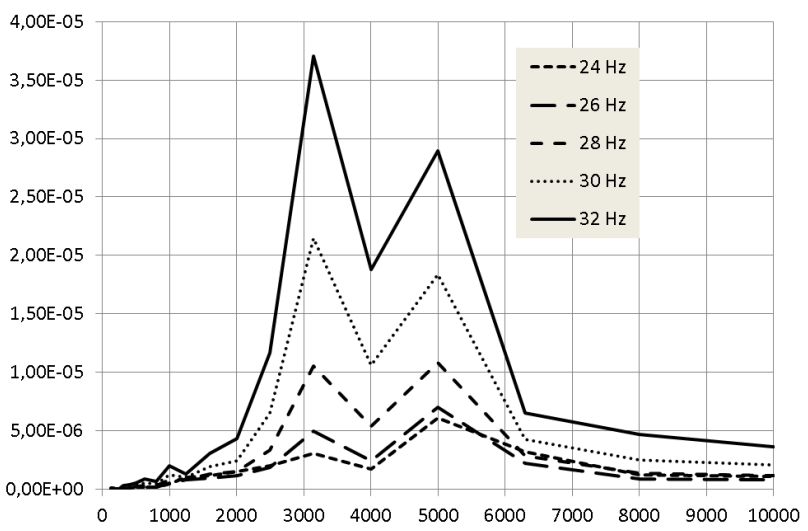

Figure 6. FFT analysis of noise measurements, frequency of motor from $24-32 \mathrm{~Hz}$

With increase of motor's frequency (which indicates increase of flow rate) the magnitudes are getting higher. The highest ones are observed at motor's frequency $32 \mathrm{~Hz}$.

The possible explanation of dividing the noise frequency into two from flow rate $3.15 \mathrm{l} / \mathrm{s}$ ( $24 \mathrm{~Hz}$ motor's frequency) is that cavitation at first is mainly of vapour type. It dominates at flow rate equal to $2.61 \mathrm{1} / \mathrm{s}$ (motor's frequency $18 \mathrm{~Hz}$ ), then the dissolved air starts to play more significant role. It is possible that two noise frequencies stands for two gases - one is undissolved air and the other is water vapour, but further studies are needed to confirm that hypothesis. 


\section{Computer simulation of cavitation}

On the basis of experimental investigation computer simulation was performed by means of ANSYS FLUENT software. The $2 \mathrm{D}$ case was calculated as the nozzle is axisymmetric. To create the proper mesh the flow without cavitation was investigated. The heights of the cells near the wall of the nozzle were set to the values that $\mathrm{y}^{*}$ parameter (wall unit) varied between 8 and 50 . The values about 8 occur only near inlet and outlet of the nozzle. It is sufficient to model boundary layer properly as far as $\mathrm{k}-\varepsilon$ turbulence model is concerned [6]. Finally, the $2 \mathrm{D}$ mesh has 21000 cells. The calculations were transient, with pressure-based solver. The gravity was taken into account. The inlet boundary condition was mass flow rate, the outlet - absolute static pressure. These parameters were known from experimental investigation.

\section{inlet}

outlet

Figure 7. Computing domain overview

\subsection{Cavitation model}

To model cavitation Schnerr \& Sauer cavitation model was chosen. This model bases on Rayleigh-Plesset equation, which states as follows [4]:

$$
r_{B} \frac{D^{2} r_{B}}{D t^{2}}+\frac{3}{2}\left(\frac{D r_{B}}{D t}\right)=\left(\frac{p_{B}-p}{\rho_{l}}\right)-\frac{2 S}{\rho_{l} r_{B}}
$$

Where : $r_{B}$ radius of bubble, $\mathrm{m} ; t$ - time, $\mathrm{s} ; p_{B}$ pressure in a bubble, $\mathrm{Pa} ; p$ pressure in the flow, $\mathrm{Pa} ; \rho_{l}$ density of liquid phase, $\mathrm{kg} / \mathrm{m}^{3} ; S$ surface tension, $\mathrm{J} / \mathrm{m}^{2}$.

In Schnerr \& Sauer model the simplifier formulas is used, when neglecting surface tension and second order term the following equation is obtained [4]:

$$
\frac{D r_{B}}{D t}=\sqrt{\frac{2}{3} \frac{p_{B}-p}{\rho_{l}}}
$$

Cavitation models in general can be gathered into two main groups [5]:

-one-fluid models (mixture models)

-two-fluid models

Schnerr \& Sauer cavitation model is one-fluid model. In these models the flow is threatened as the mixture of two phases and the conservation equations (mass and momentum) for the mixture are solved. In these models no slip between the phases is assumed. To calculate fraction of gaseous phase mass conservation equation of vapour is solved $[5,6]$.

$$
\frac{\partial \alpha \rho_{v}}{\partial t}+\nabla\left(\alpha \rho_{v} u\right)=R_{e}-R_{c}
$$

Where: $\alpha$ vapour volume fraction, $\rho_{v}-$ vapour density, $\mathrm{kg} / \mathrm{m}^{3} ; u$ mixture velocity, $\mathrm{m} / \mathrm{s} ; R_{e}, R_{c}$ source terms for evaporation and condensation respectively, $\mathrm{kg} / \mathrm{m}^{3} \mathrm{~s}$.

The main concern is mixture models is to determine the source terms $R_{e}$ and $R_{c}$. In Schnerr \& Sauer model the authors use the following formula to connect vapour volume fraction $\alpha$ with bubble radius $r_{B}$ and number of bubbles per volume of liquid $n_{B}[9]$ :

$$
r_{B}=\left(\frac{\alpha}{1-\alpha} \frac{3}{4 \pi} \frac{1}{n_{B}}\right)^{\frac{1}{3}}
$$

Then the final formulas for $\mathrm{R}_{\mathrm{e}}$ and $\mathrm{R}_{\mathrm{c}}$ :

$$
\begin{aligned}
& R_{e}=\frac{\rho_{l} \rho_{v}}{\rho} \alpha(1-\alpha) \frac{3}{r_{B}} \sqrt{\frac{2}{3} \frac{p_{S}-p}{\rho_{l}}} \\
& R_{c}=\frac{\rho_{l} \rho_{v}}{\rho} \alpha(1-\alpha) \frac{3}{r_{B}} \sqrt{\frac{2}{3} \frac{p-p_{s}}{\rho_{l}}}
\end{aligned}
$$

The model parameters were set as follows [9]:

$n_{B}=10^{13} \mathrm{~m}^{-3}, r_{B}=10^{-6} \mathrm{~m}$.

Vapour consideration in the flow was not sufficient to obtain the pressure distribution in accordance with experiment (the pressure at the inlet was too low). Therefore it was necessary to add dissolved air at the inlet of the domain. This air due to the lower pressure in the nozzle is released.

\subsection{Turbulence model}

To choose the most suitable turbulence model to the further calculation the series of tests were performed. At one frequency of pump's motor equal to $32 \mathrm{~Hz}$ (maximum flow) four different turbulence models were tested:

$$
\begin{aligned}
& \text { - } \text { k- } \varepsilon \text { RNG } \\
& \text { - } \text { k- } \varepsilon \text { realizable } \\
& \text { - } \mathrm{k}-\omega \\
& \text { - } \mathrm{SAS}
\end{aligned}
$$

The area of vapour appearance for each turbulence model is shown in figure 8 . In table 2 the outreach of vapour and gas (vapour + undissolved air) cloud is described. 
Table 2. Results of turbulence models test

\begin{tabular}{|c|c|c|}
\hline Turbulence model & $\begin{array}{c}\text { Outreach of } \\
\text { vapour cloud }\end{array}$ & $\begin{array}{c}\text { Outreach of } \\
\text { gas cloud }\end{array}$ \\
\hline $\mathrm{cm}$ & $\mathrm{cm}$ \\
\hline $\mathrm{k}-\varepsilon$ realizable & 12 & 9 \\
\hline $\mathrm{k}-\varepsilon$ RNG & 7 & 11 \\
\hline SAS & 7.5 & 9 \\
\hline k- $\omega$ & 6 & 7 \\
\hline
\end{tabular}

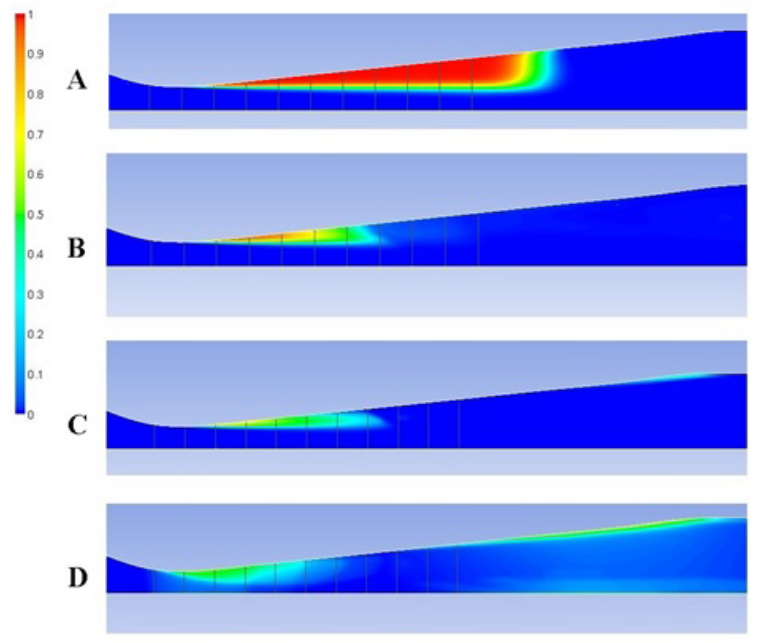

Figure 8. Vapor appearance outreach for different turbulence models: A) k- $\varepsilon$ realizable B) $k-\varepsilon$ RNG C) SAS D) $\mathrm{k}-\omega$

The analysis of the area occupied by the vapour for different turbulence models indicates that the greatest area of vapour appearance was observed while realizable k- $\varepsilon$ model was used. For k- $\omega$ model the length of the vapour cloud is too small (compared to the experiment). Moreover, for SAS and k- $\omega$ model vapor appears far away from the critical cross section, which was not observed during the experiment.

Next the dissolved air was taken into consideration. The mass flow of the air was set to the value which allows obtaining pressure at inlet close to the measured one. The area of air and both gases appearance were compared after the calculations (figure 9, 10).

Comparing area of gas appearance for different turbulence models (figure 9) it can be seen that for SAS and $\mathrm{k}-\omega$ models the area is too small in regards to experiment. For k- $\varepsilon$ models, realizable and RNG the area of gas is larger, reaching up to $9 \mathrm{~cm}$ (realizable) and 11 $\mathrm{cm}$ (RNG). The shape of the gas cloud is different - for realizable model the outreach of gas is similar near wall and along the axis of symmetry. In case of RNG mode, the gas cloud near wall is significantly shorter that along the axis. However, the analysis of areas occupied by air for different turbulence models (figure 10) shows that for realizable $k-\varepsilon$ model area of high air volume fraction occurs near wall at the length of $8-9 \mathrm{~cm}$. To investigate the reason for that discrepancy between the two k- $\varepsilon$ models the further analysis was performed.

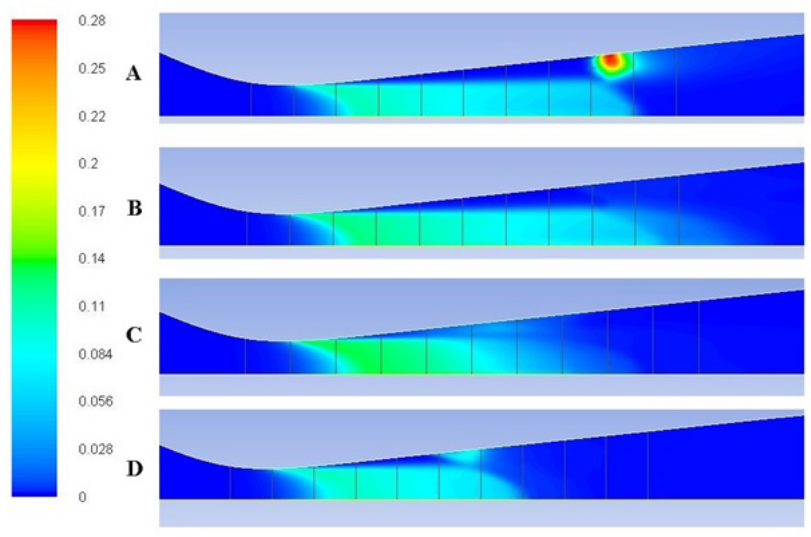

Figure 9. Undissolved air appearance outreach for different turbulence models: A) $\mathrm{k}-\varepsilon$ realizable B) $\mathrm{k}-\varepsilon$ RNG C) SAS D) k- $\omega$

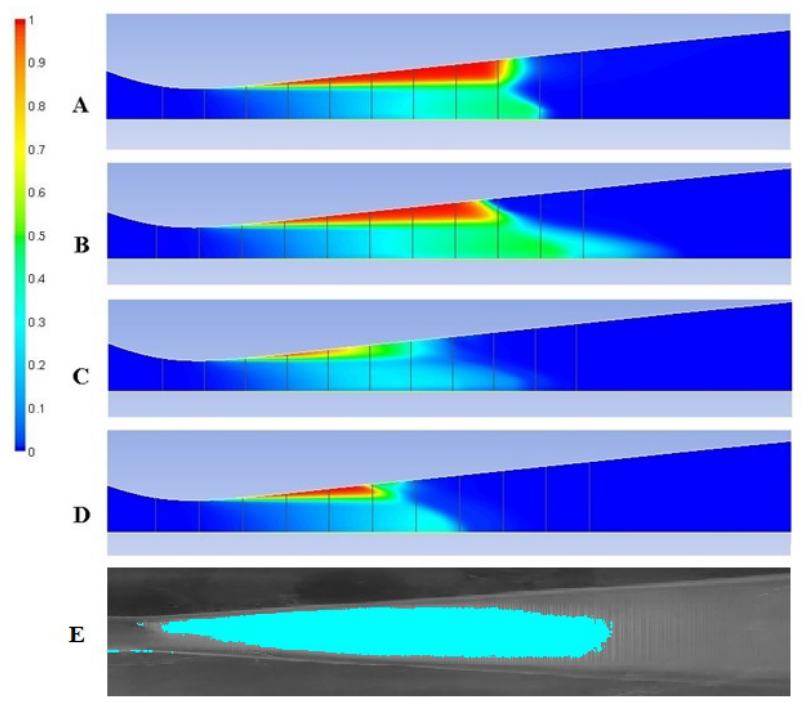

Figure 10. Gas (vapour+air) appearance outreach for different turbulence models: A) $\mathrm{k}-\varepsilon$ realizable B) $\mathrm{k}-\varepsilon$ RNG C) SAS D) k- $\omega$ E) gas area mean measured cavitation cloud

The main difference between the results obtained by RNG and realizable $\mathrm{k}-\varepsilon$ model is distribution of air along the walls of the nozzle. In figure 11 air volume fraction on the walls for both models is shown. In case of realizable $\mathrm{k}-\varepsilon$ model the sudden growth of air volume fraction is observed at $\mathrm{x}$ coordinate equal to $0.09 \mathrm{~m}$, which corresponds to the bubble of air noticed in figure 10A. The next discrepancy between the both models is wall shear stress. The distribution of this value on the walls is shown in figure 12. The highest value of this variable occurs near $0 \times$ coordinate. For realizable k$\varepsilon$ model at $\mathrm{x}$ coordinate equal to 0.09 the sudden peak of wall shear stress is observed. There is no physically based explanation for such a sudden change of this parameter. Finally, the k- $\varepsilon$ RNG model was chosen for further calculation. 


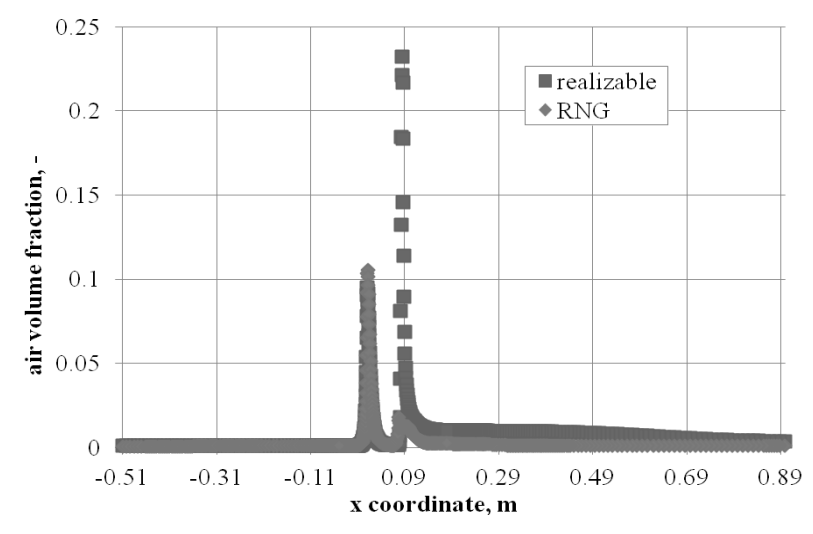

Figure 11. Distribution of air volume fraction on walls of the nozzle for RNG and realizable k- $\varepsilon$ model

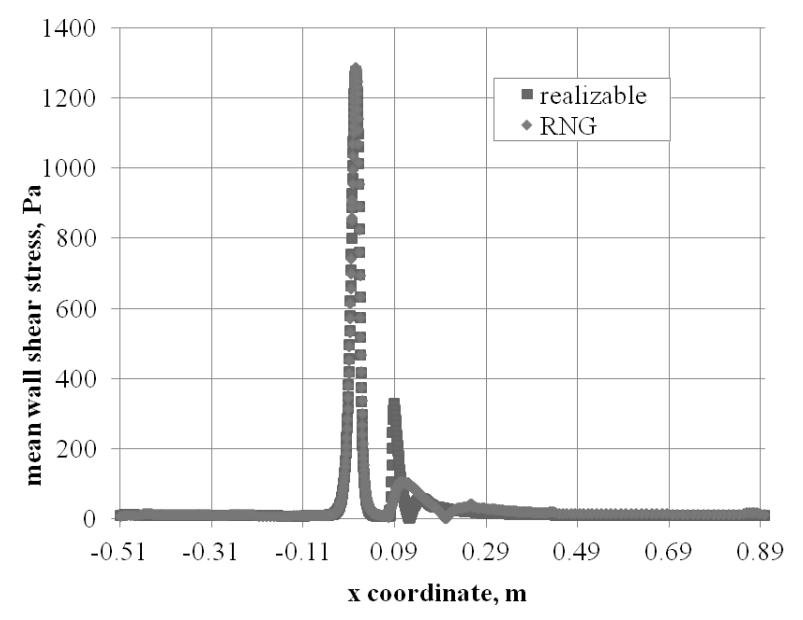

Figure 12. Distribution of mean wall shear stress for RNG and realizable k- $\varepsilon$ model

\section{Results of simulation}

After choosing the turbulence model the calculations with smaller time step $\left(\Delta \mathrm{t}=10^{-5} \mathrm{~s}\right)$ with data saving from monitor points were performed. The monitor values points were volume integrals of each phase: water, vapour and air. The results for two flow rates are presented: $2.61 \mathrm{l} / \mathrm{s}$ and $3.88 \mathrm{l} / \mathrm{s}(18 \mathrm{~Hz}$ and $32 \mathrm{~Hz}$ pump's motor respectively). With no air in the flow the pressure at the inlet obtained in calculations $\left(p_{i n l}\right)$ was lower than the one from the measurements $\left(p_{i n}\right)$. The mass flow rate of air was added $\left(Q_{a}\right)$ and set to the value which leaded to higher pressure at the inlet $\left(p_{i n 2}\right)$, which is close to the measured values.

Table 3. Details of case investigated.

\begin{tabular}{|c|c|c|c|c|c|}
\hline $\mathbf{f}$ & $\mathbf{Q}_{\mathbf{v}}$ & $\mathbf{Q}_{\mathbf{a}}$ & $\mathbf{p}_{\text {in }}$ & $\mathbf{p}_{\text {in1 }}$ & $\mathbf{p}_{\text {in2 }}$ \\
\hline $\mathrm{Hz}$ & $1 / \mathrm{s}$ & $\mathrm{kg} / \mathrm{s}$ & $\mathrm{Pa}$ & $\mathrm{Pa}$ & $\mathrm{Pa}$ \\
\hline 18 & 2.61 & $1.87 \times 10^{-6}$ & 138982 & 127000 & 138500 \\
\hline 32 & 3.88 & $5.15 \times 10^{-6}$ & 286609 & 272000 & 287500 \\
\hline
\end{tabular}

The undissolved mass flow rate is increasing with the motor's frequency, which was also observed during the experiment. For flow rate equal to $3.88 \mathrm{l} / \mathrm{s}$ the flow of the air is maintained at level of $5.15 \times 10^{-6} \mathrm{~kg} / \mathrm{s}$. In analysis of the noise frequency (section 3.2. of this paper) two main noise frequencies were observed $(5000 \mathrm{~Hz}$ and $3000 \mathrm{~Hz})$ at this flow rate. The changes of volume of air and of vapour in the domain in flow time are shown in figure 13 and 14, respectively. It can be observed that for vapour the one frequency dominates the others, in case of air volumes a few frequencies can be seen. The results of FFT analysis are shown in figure 15 (air) and 16 (vapour). The frequencies obtained by FFT analysis were 12.2 Hz, 24.4 Hz and $36.6 \mathrm{~Hz}$.

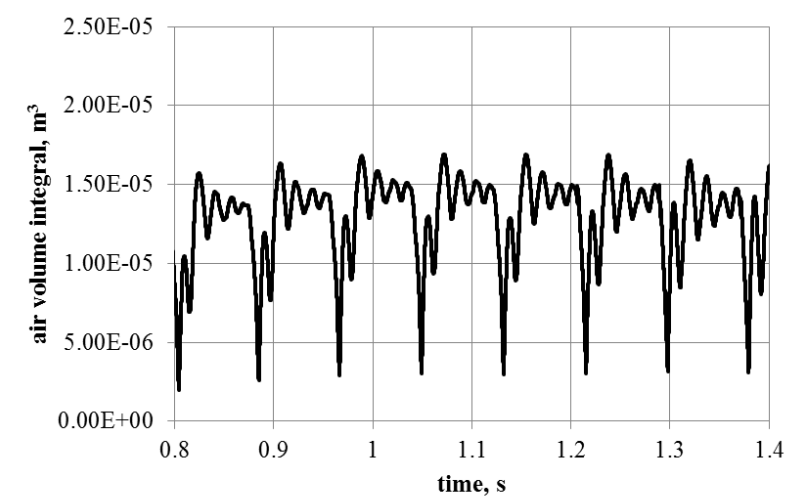

Figure 13. Volume integral of air phase in time, $32 \mathrm{~Hz}$ motor's frequency

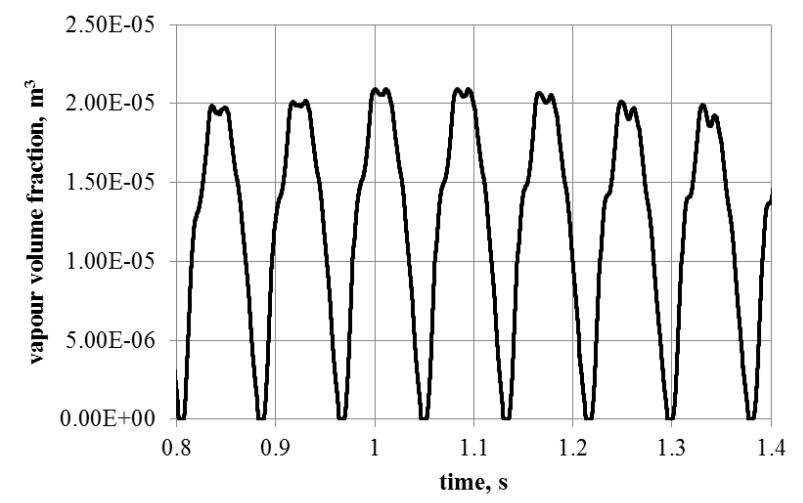

Figure 14. Volume integral of vapour phase in time, $32 \mathrm{~Hz}$ motor's frequency

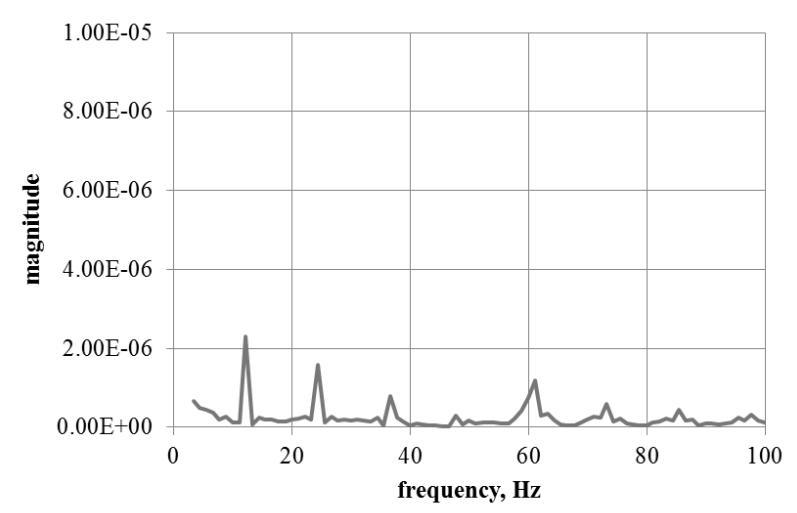

Figure 15. FFT analysis of volume integral of air phase, $32 \mathrm{~Hz}$ motor's frequency 


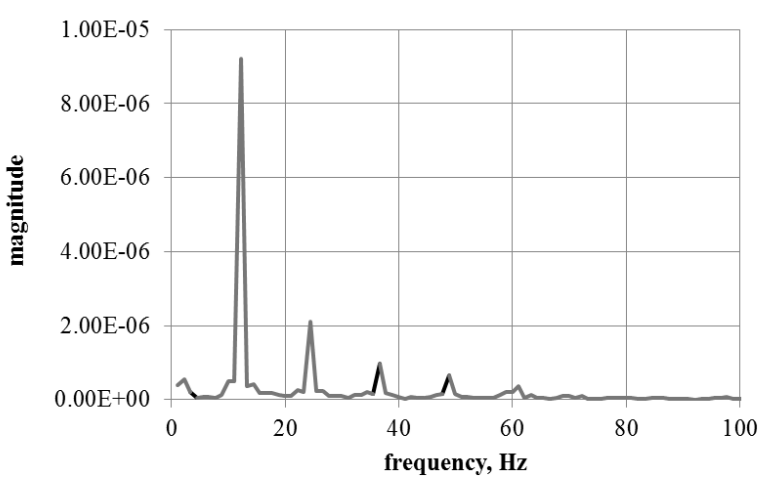

Figure 16. FFT analysis of volume integral of vapour phase, $32 \mathrm{~Hz}$ motor's frequency

Similar investigation was performed for flow rate $2.61 \mathrm{l} / \mathrm{s}$ (18 Hz pump's motor frequency). The changes of air and vapour volume in the domain in flow time are shown in figure 17 and 18, respectively. For vapour volume one frequency significantly dominates. For air volume the similar situation as for flow rate $3.88 \mathrm{l} / \mathrm{s}$ takes place - there are a few frequency of changes which covers one another. The results of FFT analysis are shown in figure 19 (air) and 20 (vapour). The frequencies obtained by FFT analysis were $37.5 \mathrm{~Hz}, 43.7 \mathrm{~Hz}$.

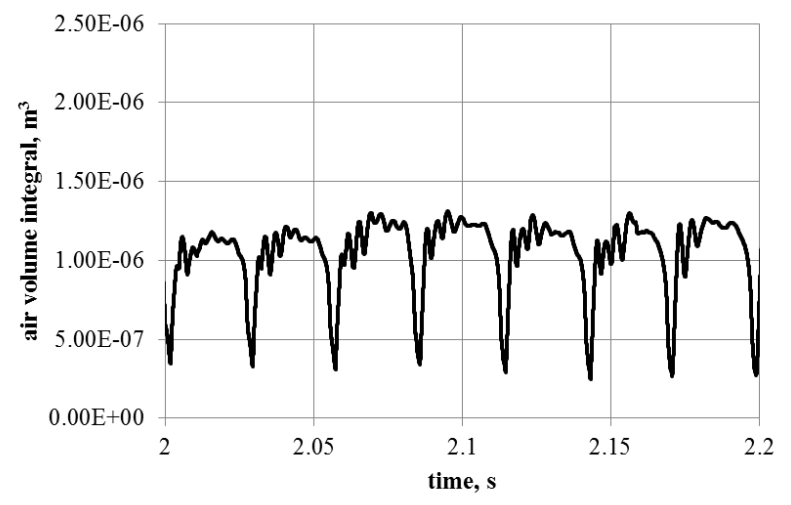

Figure 17. Volume integral of air phase in time, $18 \mathrm{~Hz}$ motor's frequency

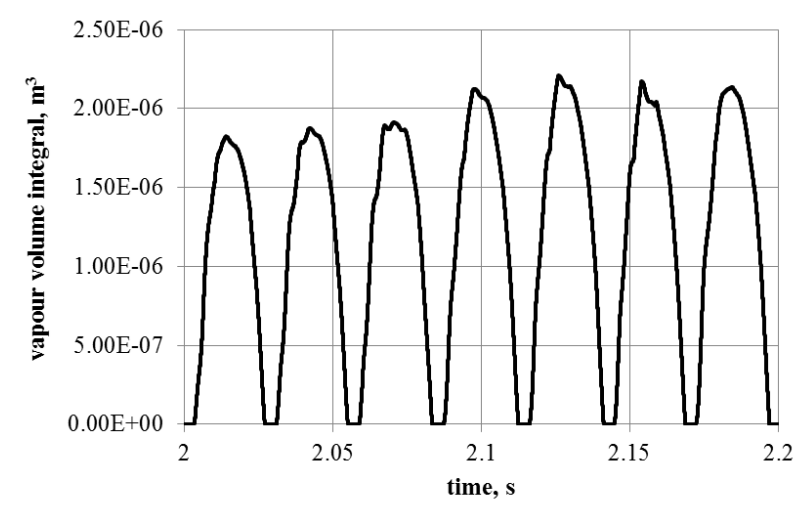

Figure 18. Volume integral of vapour phase in time, $18 \mathrm{~Hz}$ motor's frequency

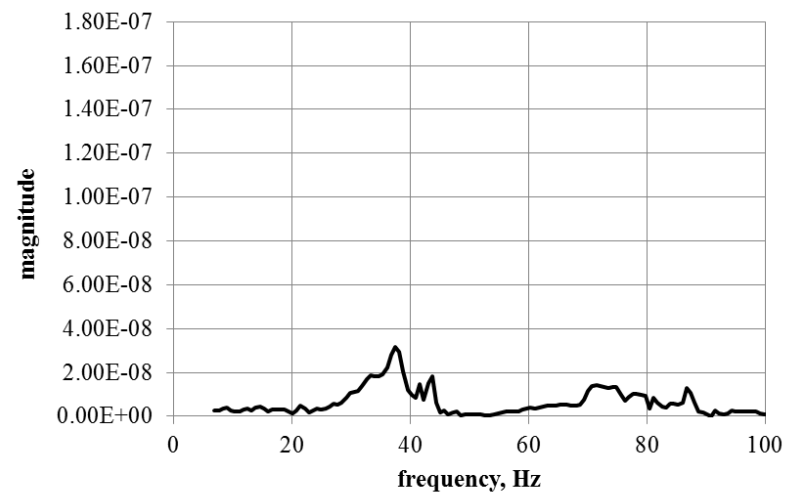

Figure 19. FFT analysis of volume integral of air phase, $18 \mathrm{~Hz}$

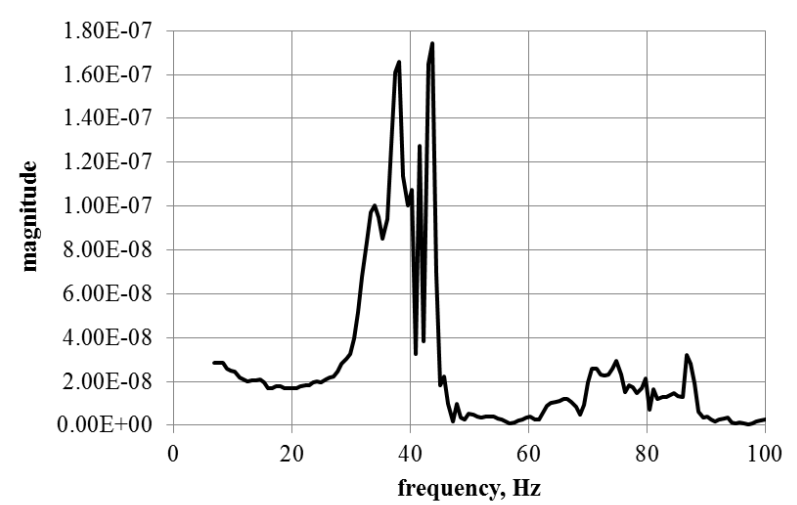

Figure 20. FFT analysis of volume integral of vapour phase, $18 \mathrm{~Hz}$ motor's frequency

After simulation performance it can be stated that in case of vapour phase there is one main growing and shrinking frequency. Meanwhile the air phase is changing with number of frequencies with no such clear domination. It also was observed that for vapour type of cavitation (which occurs at flow rate $2.61 \mathrm{l} / \mathrm{s}-18 \mathrm{~Hz}$ motor's frequency) higher frequencies of phase changing appeared. When more air is observed in cavitation cloud, the frequency of phase growing and shrinking is decreasing. That indicates that air is responsible for lower frequencies in noise analysis described in chapter 3.2.

\section{Results of 3D simulation}

To study the influence of $2 \mathrm{D}$ flow assumption the $3 \mathrm{D}$ simulation was performed. The calculation domain includes $1 / 4$ of the nozzle. The calculated case was flow rate $3.88 \mathrm{l} / \mathrm{s}$ (32 Hz pump's motor frequency). The 3D mesh contained 292000 cells. The same turbulence model was used as for $2 \mathrm{D}$ calculation $(\mathrm{k}-\varepsilon \mathrm{RNG})$. The results are shown in figure 21 and 22.

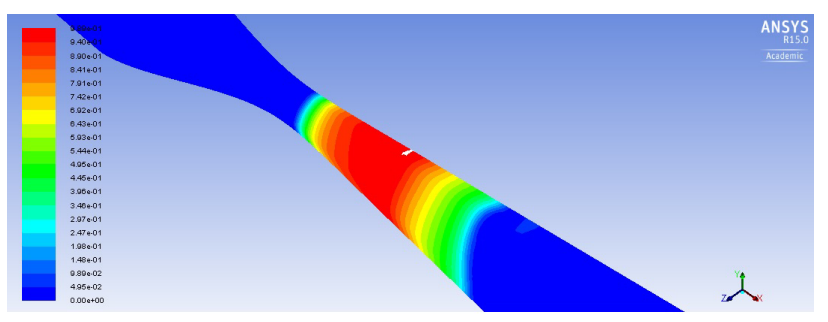

Figure 21. Vapour phase, 3D calculation 


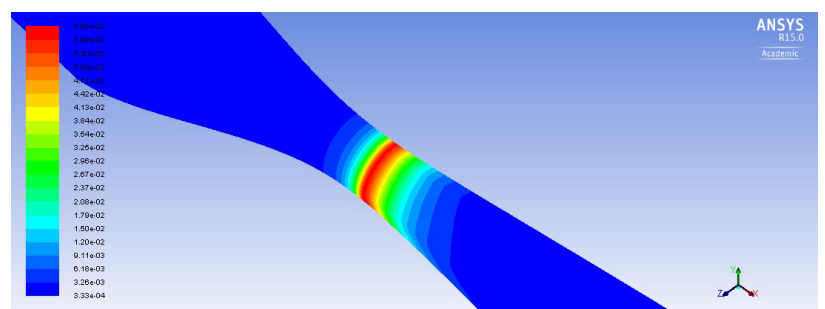

Figure 22. Air phase, 3D calculation

On basis of $3 \mathrm{D}$ calculation results it can be stated that the distribution of air and vapour volume fraction is slightly not uniform in circumferential direction on the wall. Therefore 3D calculation can provide some additional information about the shape and outreach of cavitation structures. However, this kind of calculations takes a lot more computational time than the $2 \mathrm{D}$ case. Next stage of investigation will include using LES turbulence model.

\section{Conclusions}

In the paper the experimental and numerical investigation of the cavitating flow in the water nozzle was described. The following conclusions can be provided:

First stage of cavitation was observed at pump's motor frequency equal to $18 \mathrm{~Hz}$, which stands for water flow $2.61 \mathrm{l} / \mathrm{s}$. In this case the length of cavitation structure is about $1.6 \mathrm{~cm}$. With increase of flow rate cavitation structure expands. At flow rate $3.88 \mathrm{l} / \mathrm{s}(32 \mathrm{~Hz}$ motor's frequency) the structure enlarges to $11.7 \mathrm{~cm}$. The evaluation of noise measurements results leads to conclusion that with increasing of flow rate the noise frequency split into two: instead of one frequency of $4000 \mathrm{~Hz}$ two frequencies equal to $3000 \mathrm{~Hz}$ and $5000 \mathrm{~Hz}$ are observed. This may be connected with the existence of two cavitation mechanism types: vapour and gaseous one.

Numerical investigation was performed in use of Schnerr \& Sauer cavitation model. Several turbulence models were tested. Model k- $\varepsilon$ RNG captured the best distribution of vapour and air volume fraction in the nozzle. FFT analysis of air and vapour volume changes in time in the whole domain was also performed. It showed that for first stage of cavitation higher frequency occurs than for developed one. Growing and shrinking of vapour structures appear with one main frequency, while air structures change their size with a few frequencies with similar magnitude. Analogous situation takes place for last stage of cavitation, at flow rate equal to $3.88 \mathrm{l} / \mathrm{s}$.

Although the results of FFT analysis of phases volumes changes in time cannot be compared quantitatively with noise measurements results, they are in good agreement qualitatively: the developed gas cavitation can be characterized by lower frequency than the vapour one. The frequencies observed during noise measurement are connected with frequency of single bubble, the frequencies observed during numerical simulation are related to the frequency of cavitation clouds.

$3 \mathrm{D}$ calculation with $1 / 4$ of the nozzle also was carried out. It showed that there is slightly non-uniform distribution of phases volume fractions in a circumferential direction. The further 3D calculation will be performed in the future to investigate in detail this issue.

\section{Acknowledgements}

This paper has been elaborated in the framework of the Project Intention Moravian-Silesian Region, Support for Science and research in the Moravian - Silesian Region 2014 subsidy Title1.

\section{References}

1. C. E. Brennen, Hydrodynamics of Pumps, Oxford University Press, (1994),

2. J. Noskievič, Kavitace, Praha : Ceska akademie ved, p. 509-21-875, (1969)

3. J. Jablonska, M. Bojko, Multiphase Flow and Cavitation - Comparison of Flow in Rectangular and Circular Nozzle, EPJ Conference, (2014)

4. C. E. Brennen, Cavitation and Bubble Dynamics, Oxford University Press, (1995)

5. B. Puffary, Numerical modelling of cavitation, design and analysis of high speed pumps. Educational Notes RTO-EN-AVT-143, paper 3, p. 3$1-3.54,(2006)$

6. ANSYS FLUENT 2015 User's guide

7. J. P. Franc, J. M. Michel, Fundamentals of Cavitation, Fluid Mechanics and Its Application, Volume 76, Kluwe Academic Publischers, (2004)

8. J. Jablonska, Experimentalni zarizeni $\mathrm{k}$ vzniku a vyvoji kavitace w 2D Lavalove dyze, 135/18-122013_F. submitted 18. 12. (2013)

9. G. H. Schnerr, J. Sauer, Physical and Numerical Modelling of Unsteady Cavitation Dynamics, Fourth International Conference on Multiphase Flow, New Orleans, Louisiana, (2001) 